\title{
Trends and Characteristics of Mortality Associated with Congenital Anomalies in Korean Children under 5 Years of Age
}

Soo Bin Kim, MD, Min Jung Jang, MD, Young Hwa Song, MD, Seung Yeon Jung, MD, Jun Suk Oh, MD, and Jae Woo Lim, MD

Department of Pediatrics, Konyang University College of Medicine, Daejeon, Korea

\section{ABSTRACT}

Purpose: Studies have been conducted on the prevalence and infant mortality rate of congenital anomalies; however, studies on child mortality are rare. Therefore, we evaluated the characteristics of deaths associated with congenital anomalies among children born in Korea who died within 5 years of age.

Methods: Birth-to-death cohort linked data of children under the age of 5 years from 2010 to 2013, and statistical data on the cause of death by age from 1999 to 2019, both provided by the Korea National Statistical Office's Microdata Integrated Service, were retrospectively investigated. We investigated the trends and characteristics of mortality associated with congenital anomalies.

Results: Among 1,858,945 children, 6,510 children who died were under 5 years of age, and among them, 1,229 deaths were associated with congenital anomalies, while 5,281 deaths were due to other causes. Deaths associated with congenital anomalies accounted for $18.9 \%$ of all deaths. When comparing congenital anomalies by systems, anomalies of the cardiovascular system (52.6\%) were the most common. The mortality rate associated with congenital anomalies and those of other causes showed similar declining trends in 21 years.

Conclusion: The mortality rate of congenital anomalies during the first 5 years of life did not increase differently from the prevalence of congenital anomalies but rather decreased. Deaths associated with congenital anomalies accounted for $20.5 \%$ of all infant deaths and $12.1 \%$ of child deaths, since the major causes of death in infants and children are slightly different, continuous and careful monitoring is required.

Key Words: Congenital abnormalities; Infant death; Child death

\section{INTRODUCTION}

With the advancement of diagnostic techniques such as ultrasonography, studies have
Received: 30 April 2021

Revised: 14 June 2021

Accepted: 18 June 2021

Correspondence to: Jae Woo Lim, MD

Department of Pediatrics, Konyang University College of Medicine, 158 Gwanjeodong-ro, Seo-gu, Daejeon 35365, Korea

Tel: +82-42-600-9230

Fax: +82-42-600-9090

E-mail: limsoa@hanmail.net

Copyright(c)

By Korean Society of Neonatology.

This is an Open-Access article distributed under the terms of the Creative Commons At tribution Non-Commercial License (http:// creativecommons.org/licenses/by-nc/4.0), which permits unrestricted non-commercial use, distribution, and reproduction in any medium, provided the original work is pro perly cited. 
reported a substantial increase in the reported prevalence of congenital anomalies in line with the increase in the mean age of childbirth, air pollution, and the use of endocrine-disrupting chemicals $^{1-3)}$. Based on studies conducted in South Korea, the prevalence of congenital anomalies has markedly increased from $0.6 \%$ in the 1970 s to $2.83 \%$ in the 2000 s. Compared with those in 1993-1994, diseases with a large increase in prevalence in South Korea are currently mostly mild, with little impact on mortality ${ }^{1,4)}$.

Numerous studies have investigated the prevalence of congenital anomalies and infant mortality associated with congenital anomalies $^{5-11)}$. Congenital anomalies have been reported to account for approximately $20 \%$ of infant mortality ${ }^{1)}$. Recently, con genital anomalies have been reported as the second most common cause of death in infants, after perinatal diseases. According to a recent study ${ }^{12)}$, infant mortality and overall mortality in children under 5 years of age have decreased in South Korea. Other recent studies reported that while the percentage of infectious diseases has decreased as the cause of death in infants, the percentage of congenital anomalies remains approximately unchanged ${ }^{2,5,13)}$.

Despite the significance of these reports, there is a general lack of studies regarding the annual trends and characteristics of mortality associated with congenital anomalies in South Korea each year. Notably, this is the first study to investigate mortality associated with congenital anomalies in Korean children under 5 years of age. Considering the increasing prevalence of congenital anomalies and the trend that congenital anomalies are the major cause of infant and child mortality, an accurate understanding of the mortality rate associated with congenital anomalies in child. ren under 5 years of age, the changes in mortality, and related characteristics will help improve policies to lower the rate of mortality in children.

\section{MATERIALS AND METHODS}

The data used in this study were obtained from the Microdata Integrated Service (MDIS) run by the Korea National Statistical Office. The data reported the relationship between births and deaths in Korean children under 5 years of age; these data were collected by following up children under 5 years of age born in Korea between January 1, 2010 and December 31, 2013. The data included the following information: gestational age at birth, birth weight, sex, birth region, multiple births, age, date, cause of death, as well as the age, educational background, occupation, and nationality of the parents.

The cause of death was categorized based on the Korean Stan dard Classification of Diseases and Causes of Death (KCD-7), which incorporates the latest International Classification of Dis eases and Related Health Issues, otherwise known as ICD-10, according to the status of South Korea. Specifically, the KCD-7 includes certain codes and rare disease codes that reflect the public health status in South Korea. According to the KCD-7, congenital anomalies are classified as follows: congenital malfor mations of the nervous system (Q00-Q07), congenital malfor mations of the eye, ear, face, and neck (Q10-Q18), congenital malformations of the circulatory system (Q20-Q28), congenital malformations of the respiratory system (Q30-Q34), cleft lip and cleft palate (Q35-Q37), other congenital malformations of the digestive system (Q38-Q45), congenital malformations of genital organs (Q50-Q56), congenital malformations of the urinary system (Q60-Q64), congenital malformations and deformations of the musculoskeletal system (Q65-Q79), other congenital malfor mations (Q80-Q89), chromosomal abnormalities, not elsewhere classified (Q90-Q99).

Among the 1,861,699 children born before the gestational age of 22 weeks (73 cases), those born with a birth weight of $<300 \mathrm{~g}$ (18 cases), and those with no data on the gestational age or birth weight (2,663 cases) were excluded, and the data of $1,858,945$ children were analyzed.

The data were categorized into three groups based on the gestational age: children born before 32 weeks, those born during 32 to 36 weeks, and those born on or after 37 weeks. The data were also categorized into three groups based on the birth weight: $<1.5$, $1.5-2.5$, and $2.5 \mathrm{~kg}$. The birth region was divided into two groups: Seoul and metropolitan areas (children born in Seoul, Incheon, and Gyeonggi provinces) and other areas. Concerning the num ber of births, there were two groups: single birth and multiple births. The categorization also produced the following variables based on the age, educational background, occupation, and na tionality of the parents: age $\geq 20$ and $\leq 29$ years, age $\geq 30$ and $\leq 39$ years, and age $\geq 40$ or $\leq 19$ years; education $\leq$ high school and $\geq$ college level; occupation group 1 (manager, expert or related worker, office/service worker, salesman, functional personnel, machine operator, or assembler) and occupation group 2 (manual laborer, an expert in farming, students, housewife, unemployed).

In this study, infant mortality was defined as death at the age of $<1$ year, and mortality after infancy was defined as death at the age of 1 to 4 years among children under 5 years of age, excluding 
infants under 1 year of age.

The subjects of this study were divided into three groups: surviving children (SC), child mortality associated with congenital anomalies (CMCA), and child mortality due to other causes (CMOC).

The mortality rate associated with congenital anomalies was investigated with respect to overall mortality in children under 5 years of age, as well as for different age groups: infant mortality ( $<1$ year of age) and mortality after infancy ( 1 to 4 years of age).

We additionally used complementary data related to the cause of death and mortality rate by age between 1999 and 2019 from the Korea National Statistical Office's MDIS, to investigate the overall trend of CMCA in Korean children under 5 years of age.

Demographic variables were analyzed using descriptive statistics. The risk factors that influence mortality associated with congenital anomalies were analyzed using the chi-square test and logistic regression analysis for SC vs. CMOC and SC vs. CMCA. Correlation analysis was used to clarify the trends between mor tality associated with congenital anomalies and mortality due to other causes. For all tests, statistical significance was set at $P<0.05$.

\section{RESULTS}

The demographic characteristics of the children whose data were investigated in this study were as follows: the total number of children in each of the groups were as follows: 1,852,435 child ren in the SC group, 5,281 children in the CMOC group, and 1,229 children in the CMCA group. The mean gestational age was $38.68 \pm 1.59$ weeks in the SC group, $32.8 \pm 6.35$ weeks in the CMOC group, and $36.05 \pm 4.09$ weeks in the CMCA group. The mean birth weight was $3.21 \pm 0.45 \mathrm{~kg}$ in the SC group, $2.11 \pm 1.17 \mathrm{~kg}$ in the CMOC group, and $2.49 \pm 0.84 \mathrm{~kg}$ in the CMCA group.

The simple paired comparison (performed using the chi-square test) between the SC and CMCA groups revealed a significant intergroup difference in gestational age, birth weight, multiple births, age, as well as the educational background and occupation of parents among the demographic variables. In contrast, no significant difference was found in the age at death or birth region. These variables led to similar patterns in the paired comparison between the SC and CMOC groups, except that age and birth region, in this case, showed a significant difference. An additional paired comparison between the CMOC and CMCA groups revealed a significant difference in sex, gestational age, birth weight, multiple births, age, as well as the educational backg round and occupation of parents. In contrast, no significant difference was found in the birth region (Table 1 ).

We investigated the mortality rate under 5 years of age per 1,000 children. Among 1,858,945 children, 6,510 children who died were under 5 years of age, and among them, 1,229 deaths were associated with congenital anomalies, while 5,281 deaths were due to other causes. For every 1,000 children under 5 years of age, the mortality rate associated with congenital anomalies was 0.7 , and the mortality rate due to other causes was 2.8 . The

Table 1. Demographic Characteristics of the Study Participants $(n=1,858,945)$

\begin{tabular}{lccc}
\hline Characteristic & Survival & Death due to other causes & Death associated with congenital anomalies \\
\hline Total number & $1,852,435(99.64)$ & $5,281(0.28)$ & $1,229(0.07)$ \\
Sex & & & $642(0.07)$ \\
Male & $952,102(99.62)$ & $3,001(0.31)$ & $587(0.06)$ \\
Female & $900,333(99.68)$ & $2,280(0.25)^{*}$ & $36.05 \pm 4.09$ \\
Gestational age (wk) & $38.68 \pm 1.59$ & $32.88 \pm 6.35$ & $169(1.22)$ \\
$<32$ & $11,557(83.15)$ & $2,173(15.63)$ & $283(0.28)^{\dagger}$ \\
$32-36$ & $99,450(99.09)$ & $627(0.62)^{*}$ & $777(0.04)^{\dagger}$ \\
$\geq 37$ & $1,741,428(99.81)$ & $2,481(0.14)^{*}$ & $2.49 \pm 0.84$ \\
Birth weight (kg) & $3.21 \pm 0.45$ & $2.11 \pm 1.17$ & $184(1.6)$ \\
$<1.5$ & $9,190(79.98)$ & $2,116(18.42)$ & $340(0.39)^{\dagger}$ \\
$1.5-2.49$ & $85,444(98.91)$ & $601(0.7)^{*}$ & $705(0.04)^{\dagger}$ \\
$\geq 2.5$ & $1,757,801(99.81)$ & $2,564(0.15)^{*}$ & $593(0.06)$ \\
Area of birth & & & $636(0.07)$ \\
Seoul metropolitan area & $943,764(99.69)$ & $2,424(0.26)$ & $2,857(0.31)^{*}$ \\
Other areas & $908,671(99.62)$ & & \\
\hline
\end{tabular}


Table 1. Continue

\begin{tabular}{|c|c|c|c|}
\hline Characteristic & Survival & Death due to other causes & Death associated with congenital anomalies \\
\hline \multicolumn{4}{|l|}{ Multiple birth } \\
\hline Singleton & $1,796,565(99.72)$ & $4,018(0.22)$ & $1,039(0.06)$ \\
\hline Twin or more & $55,835(98.64)$ & $678(1.2)^{*}$ & $93(0.16)^{\dagger}$ \\
\hline Missing value & $35(4.88)$ & $585(81.59)^{*}$ & $97(13.53)^{\dagger}$ \\
\hline \multicolumn{4}{|l|}{ Mother's age (yr) } \\
\hline$\leq 19$ & $10,883(98.73)$ & $130(1.18)$ & $10(0.09)$ \\
\hline $20-29$ & $606,755(99.67)$ & $1,655(0.27)^{*}$ & $355(0.06)^{\dagger}$ \\
\hline $30-39$ & $1,191,665(99.66)$ & $3,289(0.28)^{*}$ & $804(0.07)^{\dagger}$ \\
\hline$\geq 40$ & 42,139 (99.39) & $199(0.47)^{*}$ & $58(0.14)^{\dagger}$ \\
\hline Missing value & $993(99.0)$ & $8(0.8)^{*}$ & $2(0.2)^{\dagger}$ \\
\hline \multicolumn{4}{|l|}{ Father's age (yr) } \\
\hline$\leq 19$ & $2,815(99.15)$ & $22(0.77)$ & $2(0.07)$ \\
\hline $20-29$ & 280,962 (99.76) & $557(0.20)^{*}$ & $115(0.04)^{\dagger}$ \\
\hline $30-39$ & 1,367,359 (99.78) & $2,352(0.17)^{*}$ & $631(0.05)^{\dagger}$ \\
\hline$\geq 40$ & $185,472(99.67)$ & $465(0.25)^{*}$ & $140(0.08)^{\dagger}$ \\
\hline Missing value & $15,827(87.67)$ & $1,885(10.44)^{*}$ & $341(1.89)^{\dagger}$ \\
\hline \multicolumn{4}{|l|}{ Mother's educational level } \\
\hline High school graduate or below & 553,944 (99.59) & $1,833(0.33)$ & $436(0.08)$ \\
\hline College level or higher & 1,293,676 (99.76) & $2,506(0.19)^{*}$ & $650(0.05)^{\dagger}$ \\
\hline Missing value & $4,815(81.61)$ & $942(15.97)^{*}$ & $143(2.42)^{\dagger}$ \\
\hline \multicolumn{4}{|l|}{ Father's educational level } \\
\hline High school graduate or below & $526,902(99.67)$ & $1,407(0.27)$ & $351(0.07)$ \\
\hline College level or higher & 1,307,195(99.81) & $1,981(0.15)^{*}$ & $537(0.04)^{\dagger}$ \\
\hline Missing value & $18,338(89.14)$ & $1,893(9.2)^{*}$ & $341(1.66)^{\dagger}$ \\
\hline \multicolumn{4}{|l|}{ Mother's occupation } \\
\hline Group $1^{*}$ & 831,144 (99.78) & $1,466(0.18)$ & $383(0.05)$ \\
\hline Group $2^{\S}$ & $996,252(99.67)$ & $2,630(0.26)^{*}$ & $630(0.06)^{\dagger}$ \\
\hline Missing value & $25,039(94.7)$ & $1,185(4.48)^{*}$ & $216(0.82)^{\dagger}$ \\
\hline \multicolumn{4}{|l|}{ Father's occupation } \\
\hline Group $1^{\neq}$ & 1,654,071 (99.78) & $2,888(0.17)$ & $738(0.04)$ \\
\hline Group $2^{\S}$ & $139,449(99.6)$ & $435(0.31)^{*}$ & $126(0.09)^{\dagger}$ \\
\hline Missing value & $58,915(96.21)$ & $1,958(3.2)^{*}$ & $365(0.6)^{\dagger}$ \\
\hline
\end{tabular}

Values are expressed as number (\%) or mean \pm standard deviation.

*Statistically significant variables in chi-square test: survival vs. death due to other causes $(P<0.05)$; ${ }^{\dagger}$ Statistically significant variables in chi-square test: survival vs. death associated with congenital anomalies $(P<0.05){ }^{{ }^{\dagger}}$ Group 1: manager, expert or related worker, office/service worker, salesman, functional personnel, machine operator or assembler; ${ }^{\lessgtr}$ Group 2: manual laborer, expert in farming, students, housewife, unemployed.

fractional rate of congenital anomalies as the cause of death in children under 5 years of age was $18.9 \%$.

The mortality of children under 5 years of age was divided into infant mortality and mortality after infancy. Among the 5,274 infants, 1,079 deaths were related to congenital anomalies. For every 1,000 infants, the mortality rate associated with congenital anomalies was 0.5 , and the fractional rate of congenital anomalies as the cause of death in infants under 1 year of age was $20.5 \%$.
Among 1,236 children, 150 deaths were related to congenital anomalies, and for every 1,000 children aged 12 to 60 months, the mortality rate associated with congenital anomalies was 0.1 . The fractional rate of congenital anomalies as the cause of death in children aged 12 to 60 months was $12.1 \%$ (Table 2 ).

In this study, children born between 2010 and 2013 were followed up for up to 60 months. The annual rate of mortality associated with congenital anomalies showed a slightly decreasing 
Table 2. Mortality Rate under the Age of 5 Years (per 1,000)

\begin{tabular}{|c|c|c|c|c|c|c|}
\hline & \multicolumn{2}{|c|}{ 0-60 months } & \multicolumn{2}{|c|}{ 0-12 months } & \multicolumn{2}{|c|}{ 12-60 months } \\
\hline & No. & $\%$ & No. & $\%$ & No. & $\%$ \\
\hline Survival & $1,852,435$ & 996.5 & $1,858,945$ & 997.3 & $1,852,435$ & 999.4 \\
\hline Death & 6,510 & 3.5 & 5,274 & 2.7 & 1,236 & 0.6 \\
\hline Death due to other causes & 5,281 & $2.8(81.1)$ & 4,195 & $2.2(79.5)$ & 1,086 & $0.5(87.9)$ \\
\hline Death associated with congenital anomalies & 1,229 & $0.7\left(18.9^{*}\right)$ & 1,079 & $0.5\left(20.5^{*}\right)$ & 150 & $0.1\left(12.1^{*}\right)$ \\
\hline
\end{tabular}

${ }^{*}$ Fractional rate of total death.

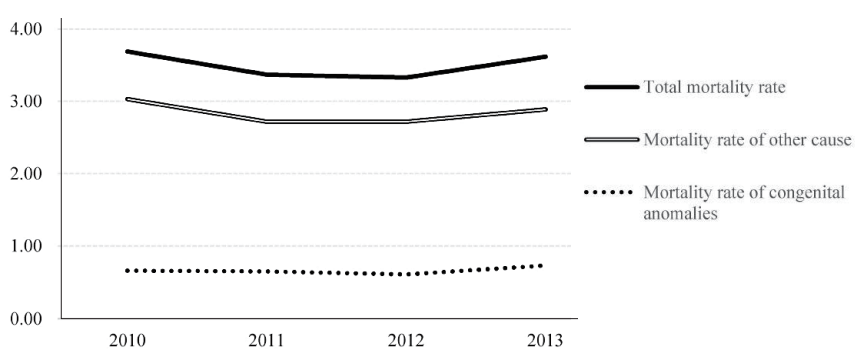

Figure 1. Annual trends of mortality rate 2010 to 2013 (per 1,000).

trend until 2012, while it increased in 2013 without a consistent trend (Figure 1).

As a complementary analysis, the data on the cause of death and mortality rate by age between 1999 and 2019 were divided into mortality associated with congenital anomalies and mortality due to other causes. Infant and CMCA and CMOC showed similar declining trends. For every 1,000 infants, the mortality rate was 1.1 and 3.6 for congenital anomalies and other causes, respectively, in 1999, while it was 0.5 and 2.2 in 2019, showing a decrease by 0.45 times and 0.61 times, respectively. For every 1,000 children aged 1 to 4 years, the mortality rate was 0.04 and 0.43 for congenital anomalies and other causes, respectively, in 1999, while it was 0.01 and 0.13 , respectively, in 2019, showing a decrease by 0.25 times and 0.3 times, respectively. Moreover, the correlation analysis of the changes between mortality associated with congenital anomalies and mortality due to other causes ac cording to birth year showed a very high correlation (rho=0.926) for infant mortality and an almost equally high correlation (rho=0.876) for mortality after infancy (Figure 2).

We also examined the proportion of deaths associated with congenital anomalies and classified deaths according to the organ system. Mortality associated with congenital anomalies for each system according to KCD-7 showed that mortality was the highest due to cardiovascular diseases (3.47 for every 10,000 children aged $<5$ years, 3.14 for infants aged $<1$ year, and 0.32 for children aged 1 to 4 years), followed by chromosomal diseases, musculoskeletal diseases, and gastrointestinal diseases, with a similar pattern despite a small change in the order between in fants (aged $<1$ year) and those aged 1 to 4 years (Figure 3 ).

The fractional rates of infant mortality and mortality after in fancy associated with congenital anomalies in each system were also investigated. For congenital anomalies of the nervous system, digestive system, and chromosomes, the fractional rates of infant mortality were $5 \%, 7.8 \%$, and $8.5 \%$, respectively, and the fractional rates of mortality after infancy were $10 \%, 12 \%$, and $14.7 \%$, respec tively. In contrast, for congenital anomalies of the cardiovascular system, the fractional rate of mortality was $54.2 \%$ for infants and $40.7 \%$ for those after infancy, indicating a fall in mortality but still with the highest proportion among the causes of death (Figure 4).

The causes of mortality associated with congenital anomalies in children under 5 years of age were investigated based on the disease: tetralogy of Fallot (TOF), patent ductus arteriosus (PDA), hypoplastic left ventricle (LV), double outlet right ventricle, double inlet ventricle, and atrioventricular septal defect. In addition to cardiovascular diseases, the diseases within the top 10 causes of mortality due to congenital anomalies are congenital diaphrag matic hernia (CDH; a musculoskeletal disease) and unspecified multiple congenital malformations in infants (aged $<1$ year) and biliary atresia (a gastrointestinal disease), Down's syndrome (a chromosomal disease), and unspecified chromosomal abnor mality (a chromosomal disease) in those after infancy (aged 1 to 4 years) (Table 3$)$.

\section{DISCUSSION}

This study investigated the rate of mortality associated with congenital anomalies in children under 5 years of age and the changes in mortality, as well as the systems and diseases majorly contributing to mortality associated with congenital anomalies. In contrast to the prevalence of congenital anomalies, the results 


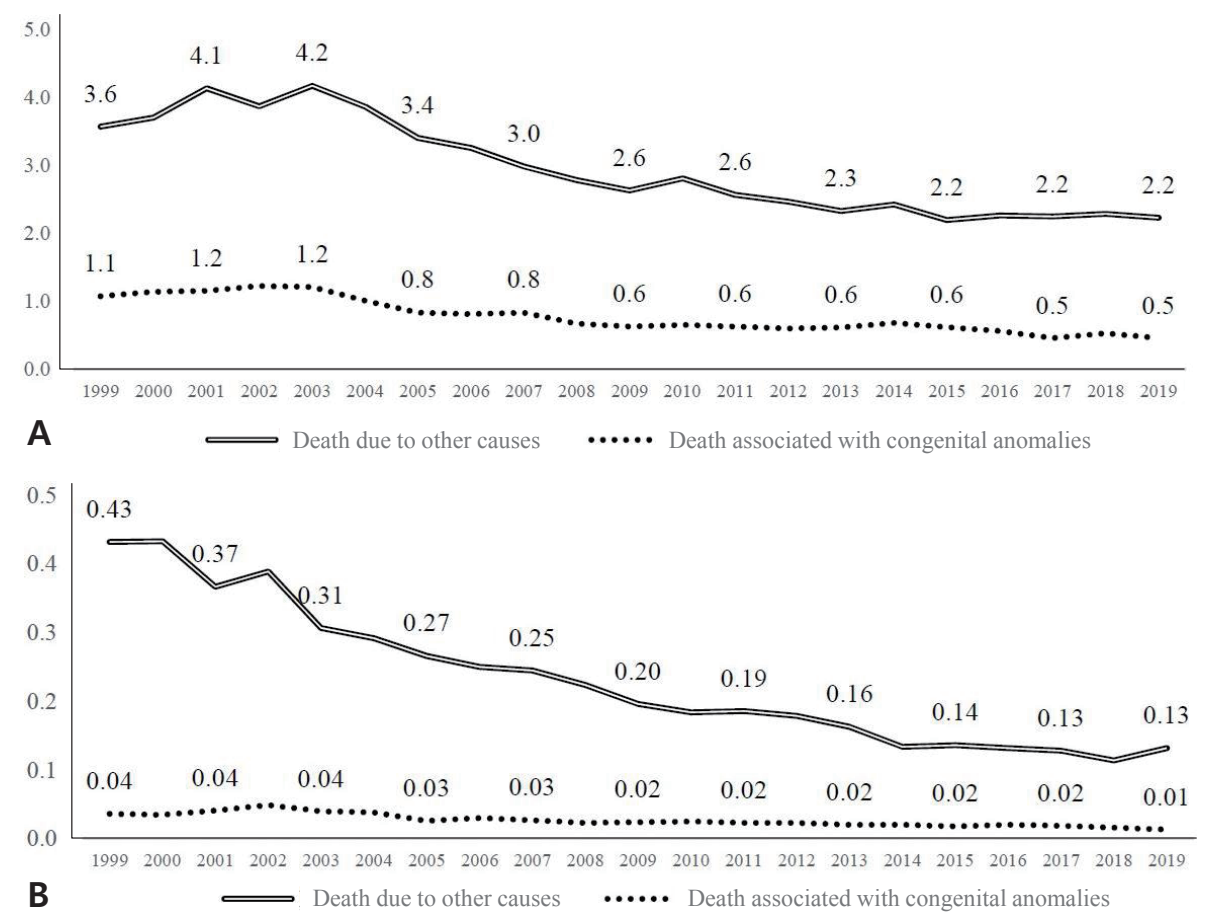

Figure 2. (A) Annual trends of mortality rate for infants under the age of 1 year, 1999 to 2019 (per 1,000). (B) Annual trends of mortality rate for children aged 1 to 4 years, 1999 to 2019 (per 1,000).

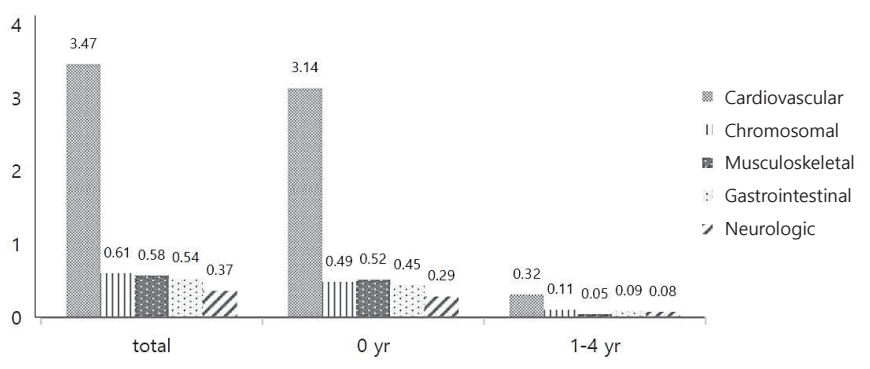

Figure 3. Mortality rate of congenital anomalies based on the system (per 10,000).

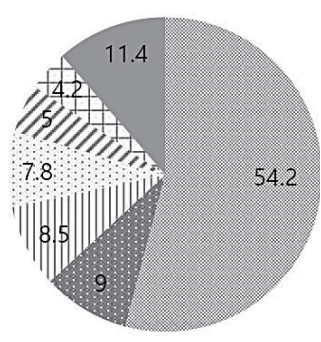

$<12$ months

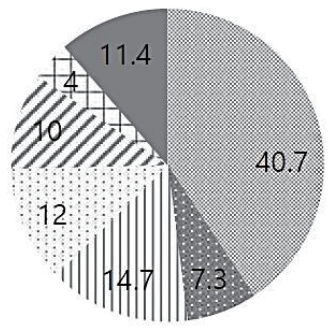

$12-60$ months
Cardiovascular

溫 Musculoskeletal

II Chromosomal

$\therefore$ Gastrointestinal

$\angle$ Neurologic

+ Respiratory
Figure 4. Mortality fractional rate of congenital anomalies based on the systems. showed that mortality associated with congenital anomalies did not increase, with a similar trend of decrease in infant mortality and mortality after infancy.

This study's analysis of the complementary data on cause of death and mortality rate by age of the past two decades (1999 to 2019) showed that infant mortality and mortality after infancy (aged 1 to 4 years) associated with congenital anomalies decreased by 0.45 times and 0.25 times, respectively, while infant mortality and mortality after infancy due to other causes also decreased by 0.61 times and 0.3 times, respectively, indicating a similar trend in overall mortality. The correlation analysis also showed a considerably high correlation.

Among the demographic variables, the factors that influenced mortality associated with congenital anomalies were gestational age, parental age, and the father's occupation. However, these variables could not be regarded as unique riskfactors for mortality associated with congenital anomalies. The risk factors for overall mortality include gestational age, parental age, birth region, multiple births, the mother's educational background, and parental occupation. There was no significant difference between the logistic regression analysis of the risk factors for CMCA in comparison to SC and the risk factors for CMOC. The risk factors for CMCA had a high correlation with the severity of anomalies 
Table 3. The Top 10 Disease-Specific Mortality Rates Associated with Congenital Anomalies, 2010-2013, Korea

\begin{tabular}{|c|c|c|c|c|c|c|}
\hline Order & Infant (0-12 months) & No. $(\%) *$ & Child (12-60 months) & No. $(\%)^{\dagger}$ & Total (0-60 months) & No. $(\%)^{\dagger}$ \\
\hline 1 & Congenital diaphragmatic hernia & $69(1.31)$ & Double inlet ventricle & $11(0.93)$ & Congenital diaphragmatic hernia & $70(1.08)$ \\
\hline 2 & Patent ductus arteriosus & $53(1.01)$ & Atresia of bile ducts & $11(0.93)$ & Tetralogy of Fallot (TOF) & $57(0.88)$ \\
\hline 3 & Tetralogy of Fallot & $51(0.97)$ & Down's syndrome, unspecified & $7(0.59)$ & Patent ductus arteriosus (PDA) & $55(0.85)$ \\
\hline 4 & Hypoplastic left heart syndrome & $48(0.91)$ & Double outlet right ventricle & $6(0.51)$ & Hypoplastic left heart syndrome & $53(0.82)$ \\
\hline 5 & $\begin{array}{l}\text { Other specified congenital malfor- } \\
\text { mation of heart }\end{array}$ & $46(0.87)$ & Tetralogy of Fallot & $6(0.51)$ & $\begin{array}{l}\text { Other specified congenital malfor- } \\
\text { mation of heart }\end{array}$ & $49(0.76)$ \\
\hline 6 & $\begin{array}{l}\text { Discordant ventriculoarterial con- } \\
\text { nection }\end{array}$ & $43(0.82)$ & $\begin{array}{l}\text { Congenital malformation affecting } \\
\text { facial appearance }\end{array}$ & $6(0.51)$ & $\begin{array}{l}\text { Multiple congenital malforma- } \\
\text { tion, unspecified }\end{array}$ & $47(0.73)$ \\
\hline 7 & $\begin{array}{l}\text { Multiple congenital malformation, } \\
\text { unspecified }\end{array}$ & $43(0.82)$ & $\begin{array}{l}\text { Chromosomal abnormality, un- } \\
\text { specified }\end{array}$ & $6(0.51)$ & Double outlet right ventricle & $45(0.7)$ \\
\hline 8 & Double outlet right ventricle & $39(0.74)$ & $\begin{array}{l}\text { Other reduction deformities of } \\
\text { brain }\end{array}$ & $5(0.42)$ & $\begin{array}{l}\text { Discordant ventriculoarterial con- } \\
\text { nection }\end{array}$ & $44(0.68)$ \\
\hline 9 & Atrioventricular septal defect & $39(0.74)$ & Hypoplastic left heart syndrome & $5(0.42)$ & Double inlet ventricle & $42(0.65)$ \\
\hline 10 & $\begin{array}{l}\text { Total anomalous pulmonary ve- } \\
\text { nous return }\end{array}$ & $38(0.72)$ & Atresia of pulmonary artery & $4(0.34)$ & $\begin{array}{l}\text { Atrioventricular septal defect } \\
\text { (AVSD) }\end{array}$ & $42(0.65)$ \\
\hline
\end{tabular}

*Fractional rate of infant mortality (\%); ${ }^{\dagger}$ Fractional rate of child mortality (\%); ${ }^{\dagger}$ Fractional rate of mortality under aged 5 years (\%).

according to the system or disease; thus, the risk factors could not yet be fully identified using the regression analysis results in this study based only on CMCA. Thus, further studies should conduct a detailed analysis of the severity and prevalence of each disease to identify the risk factors for congenital anomalies.

In this study, the highest percentage of infant mortality associated with congenital anomalies was due to anomalies in the cardiovascular system (54.2\%), musculoskeletal system (9\%), chromosomes (8.5\%), digestive system (7.8\%), and nervous system (5\%).

A similar trend was reported in a previous study ${ }^{10)}$, where infant mortality had the highest correlation with congenital anomalies in the cardiovascular system. Congenital anomalies accounted for $19.8 \%$ of infant mortality, of which $53.7 \%$ were in the cardiovascular system, $33.3 \%$ in the chromosomes, and $12.8 \%$ in the nervous system. In another study conducted in the United States ${ }^{14)}$, the percentage of mortality associated with congenital anomalies per system was $44.5 \%$ for the cardiovascular system and $22.4 \%$ for the nervous system (1970 to 1976), and during 1991 to 1997, the percentages were $36.4 \%$ for the cardiovascular system and $13.2 \%$ for the nervous system. While mortality associated with congenital anomalies in other systems decreased, mortality associated with chromosomal abnormalities showed an increasing trend.

The most significant reason for the difference among previous studies regarding the mortality due to congenital anomalies based on the system is presumed to be $\mathrm{KCD}-7$, which categorizes $\mathrm{CDH}$ as a musculoskeletal disease; $\mathrm{CDH}$ is the most common cause of infant mortality.

This study found that CDH, TOF, PDA, hypoplastic LV, and other cardiovascular conditions were the five diseases with the highest mortality rate associated with congenital anomalies in the given order among children under 5 years of age. The second to the fifth most frequent cause of mortality associated with con genital anomalies was cardiovascular disease, as reported in previous studies. The difference was that $\mathrm{CDH}$ was the most common cause. An additional analysis of child mortality due to PDA showed that the mean \pm standard deviation gestational age was $28.38 \pm 4.73$ weeks ( $\mathrm{n}=53$ ), and the mean birth weight was $1.2 \pm 0.76$ $\mathrm{kg}(\mathrm{n}=53)$. PDA seemed to be mainly correlated with very low birth weight infants.

In line with other previous foreign studies ${ }^{11,15)}$, chromosomal abnormalities were the main cause of death associated with con genital anomalies. For infant mortality associated with congenital anomalies, Down's syndrome was the 13th, Edward's syndrome was the 14th, and Patau's syndrome was the 22nd cause of death. For CMCA, Down's syndrome was the 3rd, an unspecified chro mosomal abnormality was the 7th, and Edward's syndrome was the 18th cause of death.

In contrast to previous foreign studies ${ }^{11,14,15)}$, neurological diseases ranked lower among the causes of death in this study. The conditions reported as the major cause of death in a previous study ${ }^{15}$, namely anencephaly, hydrocephaly, and failure of brain development, were all beyond the 20 th cause of death. According 
to a previous study ${ }^{15)}$, the five congenital anomalies with the highest mortality rate in infants were anencephaly, abnormal/failed renal development, Edward's syndrome, Patau's syndrome, and hypoplastic LV.

According to previous studies on congenital heart defects ${ }^{1,16)}$, hypoplastic LV had the highest mortality rate (15 in 100,000 individuals), followed by outflow tract obstruction, septal defect, and contraction of the aorta. Another study ${ }^{11)}$ on neonatal mortality reported that the most frequent cause of death among cardiovascular conditions was an unspecified congenital heart defect (65\%), among neurological diseases was neural tube defect (50\%), and among chromosomal diseases was an unspecified chromosomal abnormality (77\%).

There are certain limitations to this study. First, as the study was based only on the statistical data of the major causes of death, the severity of each congenital anomaly and multiple anomalies could not be adequately considered. A congenital anomaly as the cause of death was recorded as a single code; thus, the possibility of anomalies besides those that were the cause of death in children with multiple anomalies cannot be ruled out. Second, the data on mortality in relation to the prevalence of each disease was insuf ficient. As the study was based on a 5-year follow-up of children born between 2010 and 2013, data on the cause of death are sufficient; however, data on the prevalence of congenital malforma tions are insufficient. Therefore, we referred to existing studies on the prevalence of congenital malformations.

Global organizations such as the International Clearinghouse for Birth Defects Surveillance and Research, with 32 countries and 44 surveillance programs as its members, the European Regi stration of Congenital Anomalies and Twins in Europe, and the National Birth Defects Prevention Network in the United States have been established. As highlighted by the findings of this study, congenital anomalies exhibit an increase in prevalence and are the major cause of death in infants. Considering these issues, a continuous monitoring system should be developed at the national level to prevent congenital anomalies in the future and devise appropriate measures to treat these anomalies.

\section{ARTICLE INFORMATION}

\section{Ethical statement}

This study was approved by the Institutional Review Board of Konyang University Hospital (Approval number: KYUH 2020-
07-008). Informed consent was not applicable because this study is retrospective study based on the data from Korean Statistical Information Service.

\section{Conflicts of interest}

No potential conflict of interest relevant to this article was reported.

\section{Author contributions}

Conception or design: S.B.K., J.W.L.

Acquisition, analysis, or interpretation of data: S.B.K., J.W.L.

Drafting the work or revising: S.B.K., M.J.J., Y.H.S., S.Y.J., J.S.O., J.W.L.

Final approval of the manuscript: S.B.K., J.W.L.

\section{ORCID}

Soo Bin Kim https://orcid.org/0000-0002-6648-6002

Jae Woo Lim https://orcid.org/0000-0003-2001-0727

\section{REFERENCES}

1. Chung SH, Kim HY, Kim JH, Choi YS, Lee BS, Kim KS, et al. Changing patterns of congenital anomalies over ten years in a single neonatal intensive care unit. Korean J Perinatol 2013;24: 11-9.

2. Tomatir AG, Demirhan H, Sorkun HC, Koksal A, Ozerdem F, Cilengir N. Major congenital anomalies: a five-year retrospective regional study in Turkey. Genet Mol Res 2009;8:19-27.

3. Lamichhane DK, Leem JH, Park M, Kim JA, Kim HC, Kim JH, et al. Increased prevalence of some birth defects in Korea, 20092010. BMC Pregnancy Childbirth 2016;16:61.

4. Choi JS, Seo K, Han YJ, Lee SW, Boo YK., Lee SW, etal. Congenital anomaly survey and statistics. Sejong: Korea Institute for Health and Social Affairs, 2009: Report No: 11-1351000-000517-12.

5. Centers for Disease Control and Prevention. Leading causes of death and numbers of deaths, by age: United States, 1980 and 2016 [Internet]. Atlanta: CDC; 2021 [cited 2021 Aug 5]. Available from: https://www.cdc.gov/nchs/data/hus/2017/020.pdf.

6. Chung SH, Choi YS, Bae CW. Changes in the neonatal and infant mortality rate and the causes of death in Korea. Korean J Pediatr 2011;54:443-55.

7. Wen SW, Liu S, Joseph KS, Trouton K, Allen A. Regional patterns of infant mortality caused by lethal congenital anomalies. Can J Public Health 1999;90:316-9.

8. Rosano A, Botto LD, Botting B, Mastroiacovo P. Infant mortality 
and congenital anomalies from 1950 to 1994: an international perspective. J Epidemiol Community Health 2000;54:660-6.

9. Kurinczuk JJ, Hollowell J, Boyd PA, Oakley L, Brocklehurst P, Gray R. The contribution of congenital anomalies to infant mortality [Internet]. Oxford: National Perinatal Epidemiology Unit, University of Oxford; 2010 [cited 2021 Aug 5]. Available from: http://www.npeu.ox.ac.uk/infant-mortality.

10. Nacher M, Lambert V, Favre A, Carles G, Elenga N. High mortality due to congenital malformations in children aged $<$ 1year in French Guiana. BMC Pediatr 2018;18:393.

11. Roncancio CP, Misnaza SP, Pena IC, Prieto FE, Cannon MJ, Valencia D. Trends and characteristics of fetal and neonatal mor tality due to congenital anomalies, Colombia 1999-2008. J Matern Fetal Neonatal Med 2018;31:1748-55.

12. Jang MJ, Song YH, Yoon JM, Cheon EJ, Ko KO, Lim JW. Mortality rate and major causes of death by gestational age in Korean children under 5 years of age. J Korean Med Sci 2020;35:e340.

13. Singh K, Krishnamurthy K, Greaves C, Kandamaran L, Nielsen AL, Kumar A. Major congenital malformations in Barbados: the prevalence, the pattern, and the resulting morbidity and mortality. ISRN Obstet Gynecol 2014;2014:651783.

14. Lee K, Khoshnood B, Chen L, Wall SN, Cromie WJ, Mittendorf RL. Infant mortality from congenital malformations in the United States, 1970-1997. Obstet Gynecol 2001;98:620-7.

15. Wang Y, Hu J, Druschel CM. A retrospective cohort study of mortality among children with birth defects in New York State, 19832006. Birth Defects Res A Clin Mol Teratol 2010;88:1023-31.

16. Boneva RS, Botto LD, Moore CA, Yang Q, Correa A, Erickson JD. Mortality associated with congenital heart defects in the United States: trends and racial disparities, 1979-1997. Circulation 2001; 103:2376-81 